\title{
Some cultural differences in sanctioning behavior'
}

MARVIM E. SHAW

UNIVERSITY OF FLORIDA

Forty-eight Ss responded to a questionnaire which incorporated structural and outcome variables known to be related to sanctioning behavior in the United States. Twelve Ss represented each of two age groups (11-13 and 16-19) and two nationalities (Cuban and U. S.). Results showed considerable cultural generality in the operation of variables influencing sanctioning behavior, but the strength of these variables was a function of age, nationality, outcome quality, and outcome intensity.

Sanctioning behavior has long been recognized as a significant factor in interpersonal behavior, but, surprisingly, most research has been devoted to a simple demonstration that such behavior does occur (Roethlisberger \& Dickson, 1939; Gross, McEachern, \& Mason, 1958). A notable exception is the work of Sulzer (1964) who demonstrated that attribution of responsibility to another person for an outcome (event, happening) provides the basis for sanctioning that person. He also showed that sanctioning behavior is influenced by at least some of the same variables as attribution of responsibility-namely, association, commission, foreseeability, intentionality, justification, outcome quality, and outcome Intensity (Shaw \& Sulzer, 1964).

In theory, young children initially attribute responsibility and assign sanctions on the basis of association alone: If a person is associated with a given outcome he is open to sanctions with respect to that outcome. He leams to take into account other variables as he undergoes socialization (Piaget, 1932; Heider, 1958). Thus, there is reason to question the generality of Sulzer's findings. Is sanctioning behavior by members of different cultures influenced by these same variables? If so, are some variables relatively stronger in one culture than in another? The present experiment attempted to provide some evidence concerning these questions by comparing two cultures differing in childrearing practices: Cuba and the United States. Grossly speaking, the Cuban culture places relatively more emphasis upon rewards for good behavior and upon dependence (Stuart \& Eliasberg, 1962), whereas the U. S. culture places relatively more emphasis upon punishment for bad behavior and upon independence (Child, 1954; Sears, Maccoby, \& Levin, 1957). The emphasis on dependence could lead to greater identification with authority on the part of Cubans, and hence a stronger tendency to sanction than U.S. Ss. The emphasis on rewarding should lead to greater sanctions for positive outcomes in the Cuban than in the U.S. culture. Therefore, it was expected that the same variables would operate in both cultures, but that the Cubans would assign greater sanctions than U. S. Ss, especially for positive outcomes. Since the effects of childrearing practices should be greater for younger than for older persons, these effects should show up more strongly in younger age groups.

Methed

The experimental design involved two nationalities (Cuban and U. S.), two age groups (11-13 and 16-19 years), two outcome qualities (positive and negative), two outcome intensities (high and low), and five levels of sophistication (as outlined by Heider and described below). The Ss were 24 Cuban refugees who had been in the United States no longer than five years and 24 native U. S. citizens, all drawn from Dade County Public Schools, Florida. Half of the Ss in each nationality group were male and half were female, and half of each subgroup represented each age classification. The four experimental groups thus created were matched as closely as possible for social class and intelligence, although the evidence regarding intelligence was not entirely satisfactory.

Ss were administered a 20-item form of the AS Questionnaire. This consists of short stories designed to represent Heider's (1958) levels and the outcome quality and intensity variables, and is similar to the AR Questionnaire used by Shaw \& Sulzer (1964). Each story at a given level includes only the minimum factors necessary to elicit sanctioning behavior by a person functioning at that level of development. Stories at Level I include only association (the central figure is associated with the event or outcome, but does not produce the outcome by his own actions), stories at Level II add commission, and stories at Levels III, IV, and $V$ add successively foresecability, intentionality, and justification. Each level is represented by four stories, involving all combinations of high and low outcome intensity and positive and negative outcomes. The two-forms reliabllity was found to be .81 for a sample of 22 7-8 year old children and .98 for a group of 37 high school students. Valldity was indicated by the judgments of 27 college students concerning the variables represented by the stories. The Cuban Ss were given a Spanish version derived by the translation-retranslation procedure by two independent translators.

The stories were read in the classroom by the Ss' homeroom teacher. Ss responded by circling either YES or NO on an answer sheet and, if they clrcled YES, by checking one of five boxes to indicate degree of sanctioning. Scores ranged from zero for no sanction to 5 for maximum sanction. 


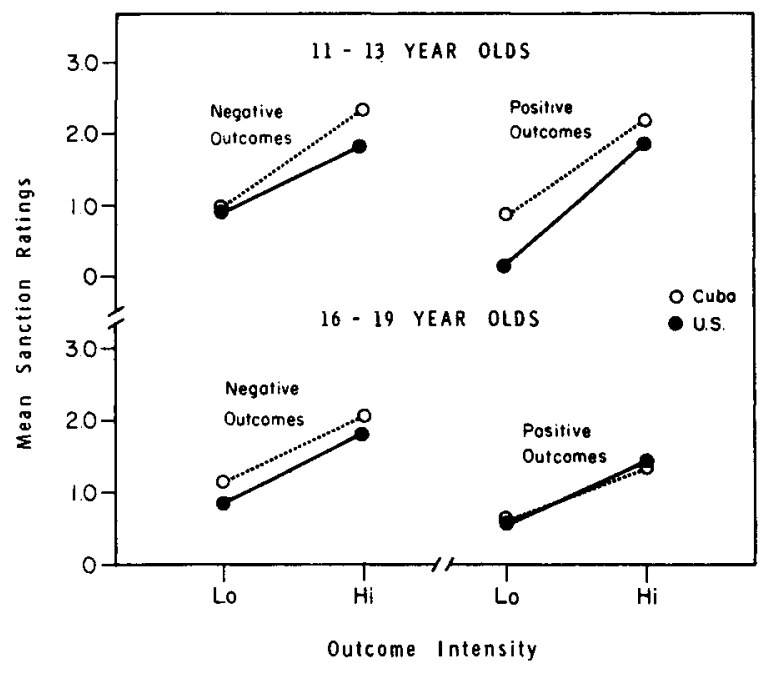

Fig. 1. Sanctions as a Function of Age, Nationality, Outcome Quality, and Outcome Intensity.

\section{Results}

Analysis of variance revealed significant effects produced by: Levels ( $F=233.95, \mathrm{df}=4 / 836, \mathrm{p}<.001)$, Outcome Quality ( $F=28.21$, df $=1 / 836, p<.001$ ), Outcome Intensity ( $F=230.56, d f=1 / 836, p<.001)$, Nationality $(F=4.23, \mathrm{df}=1 / 44, \mathrm{p}<.05)$, Levels by Outcome Quality $(F=54.70, \mathrm{df}=4 / 836, \mathrm{p}<.001)$, Levels by Outcome Intensity $(F=49.44, d f=4 / 836, p<.001)$, Age by Outcome Intensity $(\mathrm{F}=7.69, \mathrm{df}=1 / 836, \mathrm{p}<.01)$, Levels by Outcome Quality by Outcome Intensity ( $F=22.14$, $\mathrm{df}=4 / 836, \mathrm{p}<.001$ ), and Outcome Quality by Outcome Intensity by Age by Nationallty $(F=3.04, \mathrm{df}=1 / 836$, $\mathrm{p}<.05)$.

With the exception of Nationality and the higher order interaction involving Nationality, the findings represent replications of earlier results (Sulzer, 1964). In all groups, sanctions increased in magnitude from Level I to Level IV and decreased at Level V. Sanctions were greater for negative than for positive outcomes and for high intensity than for low intensity outcomes, but the magnitude of these effects was greater at Levels II, III, and V than at Levels I and IV.

A major interest of this research lies in differences in nationalities, which are reflected primarily in the significant Outcome Quality by Outcome Intensity by Age by Nationality interaction, shown graphically in Fig. 1. The greatest differences occur in the 11-13 year age group with positive outcomes, although a significant difference also occurs with high intensity, negative outcomes for this age group. Noticeable, but nonsignificant, differences occur in the 16-19 age groups with negative outcomes.

\section{Discussion}

There are two conclusions that may be drawn from these results. First, there is considerable cultural similarity with regard to the variables which influence sanctioning behavior. Second, the magnitude of the effects produced by age and outcome variables is different for the two cultures, but the levels variables exert essentially the same effects in both nationality groups. The first conclusion is significant in that it adds to the growing body of evidence showing much more cultural generality in social behavior than was once believed to be the case. It is possible, of course, that greater international mobility has led to greater cultural generality.

The second conclusion is generally in accord with the notion that sanctioning behavior is related to childrearing practices in the two cultures. With few exceptions, Cuban Ss assigned greater sanctions than did U. S. Ss, although significant differences were found only among the 11-13 age group. This is consistent with the hypothesis that "sophistication" in sanctioning behavior develops at different rates as a function of cultural factors, but reaches a final stage which is essentially the same regardless of early experiences.

The expectation of greater cultural differences with positive outcomes is only partially supported.

\section{References}

Child, I. L. Socialization. In G. Lindzey (Ed.), Handbook of social psychology. Cambridge, Mass.: Addison-Wesley, 1954. Fp. 655692.

Gross, N., McEachem, Q. W., \& Mason, W. S. Role conflict and its resolution. In E. E. Maccoby, T. M. Newcomb and E. L. Hartley (Eds.), Readings in social psychology. (3rd ed.) New York: Holt, 1958. Pp. 447-459.

Heider, F. The psychology of interpersonal relations. New York: Wiley, 1958.

Piaget, J. The moral judgment of the child. New York: Harcourt, Brace, 1932.

Roethlisberger, F.J., \& Dickson, W. J. Management and the worker. Cambridge, Mass.: Harvard University Bus. Res. Studies, 1939, 21 , No. 9 .

Sears, R. R., Maccoby, E. E., \& Levin, H. Patterns of child rearing. New York: Harper \& Row, 1957.

Shaw, M. E., \& Sulzer, J. L. An empirical test of Heider's levels in attribution of responsibility. J. abnorm. soc. Psychol., 1964, $69,39-46$.

Stuart, I. R., \& Eliasberg, W. G. Personality structures which reject the human form in art: An exploratory study of cross-cultural perceptions of the nude. J. soc. Psychol., 1962, 57, 383-389.

Sulzer, J. L. Attribution of responsibility as a function of the structure, quality, and intensity of the event. Unpublished doctoral dissertation, University of Florida, 1964.

\section{Note}

1. This research was supported by NSF Grant GS-647. Grateful acknowledgment is made to May E. Briscoe for her assistance in collecting the data and to Leonardo Rodrigues and Joel GarciaEsteve for translating the AS Questionnaire. 